Working Paper 2003-12-02

December 2003

\title{
Distribution of Cross-Section of Price Changes and Measurement of Inflation
}

Vineet Virmani vineet@iimahd.ernet.in

Indian Institute of Management, Ahmedabad 


\section{Distribution of Cross-Section of Price Changes and Measurement of Inflation}

In this study we look at the statistical properties of components forming the Wholesale Price Index (WPI), the headline inflation index for the Indian economy. We find that not only is the distribution of price changes at the disaggregate level highly leptokurtic, but also the cross-sectional distribution of price changes is positively skewed. This has the implication that the weighted mean would fail to be an efficient estimator of inflation. Trimmed Means, belonging to the class of limited influence estimators, have been used by many central banks to get around the skewness problem. We also explore the use of trimmed means for efficiently estimating inflation for India. In particular, we study the robustness of trimmed means to the benchmark (Centered Moving Average vs. trends derived from the Hodrick Prescott Filter) and the evaluation criteria (Mean Absolute Deviation vs. Root Mean Square Error vs. an Asymmetric Loss Function). Although we study the performance of trimmed means against the weighted mean in some detail, we stop short of proposing any 'one' trimming pattern as the ideal. The selection of the headline inflation rate depends as much on its ability to track the underlying trend void of transitory disturbances as much on its ability to forecast future inflation and its correlation with money growth, something we don't deal with in the present study.

\section{Introduction}

It is a known statistical fact that sample draws from Gaussian distributions of different variances result in a leptokurtic distribution. Also, if the original distribution is fat-tailed the sample draws are often highly skewed. In India the headline inflation rate is based on the weighted means of price changes in sub-components forming the Wholesale Price Index (WPI). Even if the underlying distribution of price changes is Gaussian, we are faced with the possibility of skewed cross-sectional samples. If that is indeed the case, mean won't be an efficient estimator of inflation.

Following the works of Cecchetti and others ${ }^{1}$ at the National Bureau of Economic Research (NBER) on the measurement of core inflation, we study the possibility of using trimmed means as efficient estimators of inflation for India. Though a work on similar lines on measuring core inflation was done for India too by Mohanty, Rath and Ramaiah (2000), the treatment of statistical properties of the underlying sub-components was at best cursory. Also, not only was the study based on the WPI at 1981-82 prices (and weights), only three possible trimming patterns were evaluated $(5,10$ and 15 from each tail). As we show later, the distribution of the cross-section of samples is positively skewed which means that if we trim the tails symmetrically, the trimmed mean will be biased downwards. We deal with this issue by evaluating all possible (50 X 50) combinations of trims from both tails.

The plan of the paper is as follows. In Section II we briefly discuss the theory of core inflation, and see why the use of limited influence estimators makes sense for tracking the underlying trend inflation. In Section III we study the statistical properties of WPI and its sub-components, including the behaviour of higher order moments viz., skewness and kurtosis. In Section IV we describe the use of trimmed means as estimators of

\footnotetext{
${ }^{1}$ See Bryan and Cecchetti (1993, 1996), Cecchetti (1996), and Bryan, Cecchetti and Wiggins (1997)
} 
inflation and delineate our criteria of evaluation. In particular we study the robustness of trimmed means to the benchmark (Centered Moving Average (CMA) vs. trends derived from the Hodrick-Prescott (HP) Filter) and the criteria of evaluation (Mean Absolute Deviation (MAD) vs. Root Mean Square Error (RMSE) vs. an Asymmetric Loss Function (ALF) that we describe later). In Section $\mathbf{V}$ we conclude by presenting our results and comparing the performance of trimmed means with mean and weighted median.

\section{Core Inflation}

The discussion of core inflation in monetary literature revolves around the belief that there is ' $a$ ' measure of inflation that ought to be tracked by the central bank, and since transmission lags are largely unknown, short term inflation developments should not unduly affect the bank's monetary policy decisions.

According to Blinder (1982) core inflation is that component of inflation that results from interaction between aggregate demand and aggregate supply. This implies that to model core inflation we need a complete macroeconomic model of how prices get determined in the economy. As Bryan and Cecchetti (1993) argue

"If money growth were truly exogenous, one could measure core inflation by estimating [this] reduced form and then looking only at the portion of inflation that is due to past money growth and the permanent component of the shocks"

Ideally we would like to have our measure of core inflation from the available price data, because not only a large scale macroeconomic model vulnerable to the Lucas critique, as Bryan and Cecchetti (1993) put quite succinctly, it is also "...difficult to formulate and easy to criticize.",

Before we move any further let us look at Figure 1, which shows the evolution of weighted higher order moments of the cross-section of distribution of price changes forming the WPI. Though we analyse the distributional properties in detail later, for now note that not only the cross-section of price changes exhibit extremely high kurtosis it also displays significantly positive skewness on an average. We are interested in what causes this skewness, because if the distributions have such high positive skewness simple weighted mean would be a biased estimator of inflation.

Figure 1

\footnotetext{
${ }^{2}$ Michael F. Bryan and Stephen G. Cecchetti (1993), Measuring Core Inflation, NBER Working Paper No. 4303, footnote \# 3, p. 3

${ }^{3}$ ibid p. 3
} 

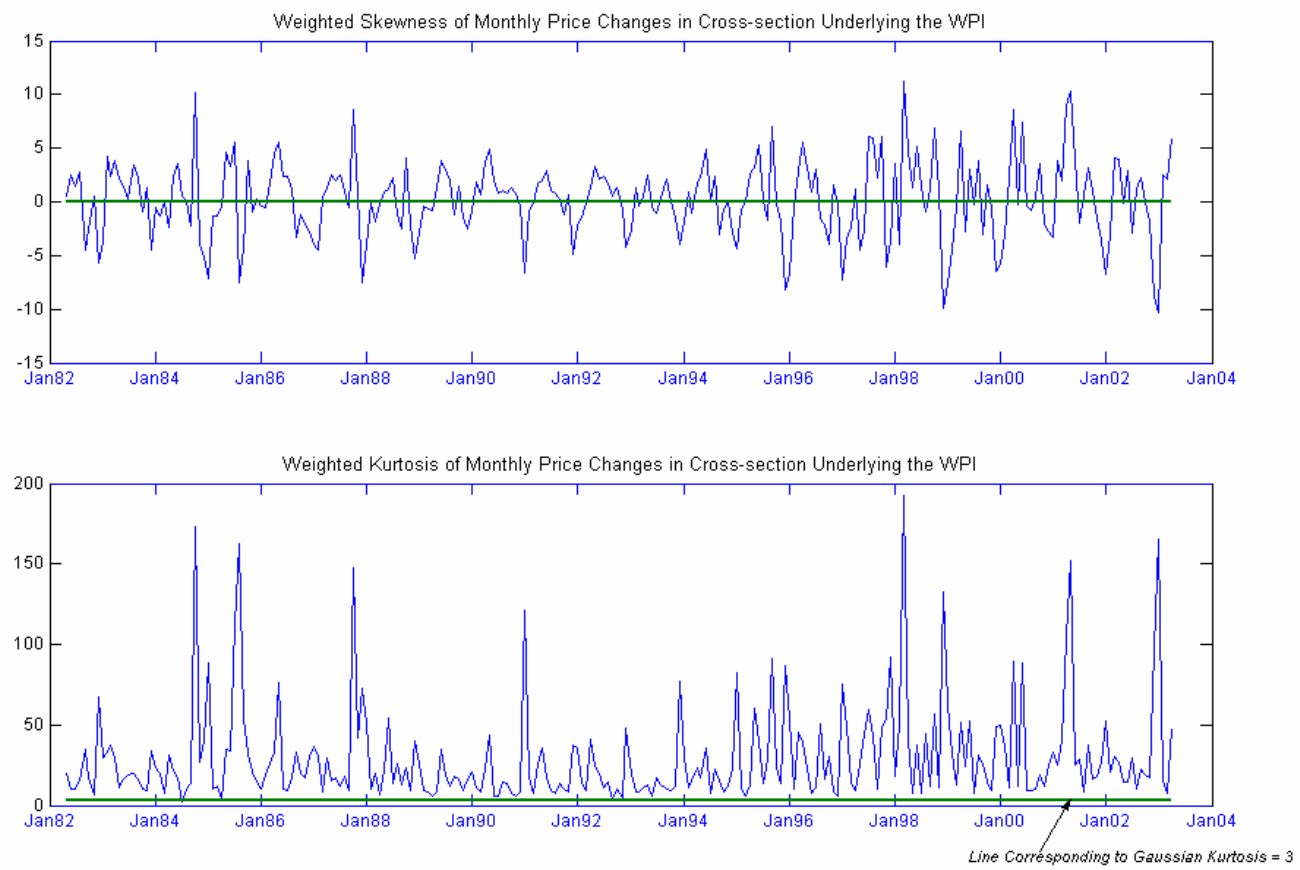

Dealing with the issue of core inflation as a statistical matter has found considerable support in recent times. Made popular by Bryan and Cecchetti (1993) and refined by Bryan Cecchetti and Wiggins (1997) and others, theoretically the approach of Bryan and Cecchetti (1993) is based on Ball and Mankiw's (1995) menu cost model ${ }^{4}$.

According to Ball and Mankiw (1995), because menu changes are expensive, not all price setters respond to (what seem to be) temporary demand/supply shocks. Now if only the firms that are extraordinarily affected by these shocks change their prices, only in the case of completely symmetric price shocks would the distribution of aggregate price changes remain symmetric. In their model price shocks are asymmetric, and depending on the skewness in the distribution of the shocks, the aggregate price change distribution would be either positively or negatively skewed.

The other model that explains why the shape of the cross-sectional distribution of price changes could be asymmetric is that of Balke and Wynne (1996), who propose a multisectoral flexible-price dynamic general equilibrium model, again with asymmetric price shocks, which results in a positive correlation between mean and skewness.

In any case, whether one believes in the asymmetric price shocks based menu costs models or not, we know from statistics that random draws from leptokurtic distribution are likely to produce skewed samples. Roger (1997) shows that for highly leptokurtic distributions, irrespective of skewness, mean ceases to be the most efficient measure of

\footnotetext{
${ }^{4}$ Ironically in a later study it is Bryan and Cecchetti (1996) themselves who find little evidence supporting positive correlation between mean and skewness in the distribution of price changes for US CPI
} 
central tendency. As we see later, not only the distribution of price changes in individual sub-components highly leptokurtic, the distribution of cross-section of price changes underlying the WPI is also highly skewed.

Although there are have been other approaches too for modeling core inflation they have only found limited acceptance (see Vega and Wynne (2001)). The limited-influence estimator technique, a most intuitive approach given the observed skewness in price changes, has been found to be the most robust and the most accepted one across countries. $^{5}$

Two important criteria of robustness for a measure of core inflation is the degree of its correlation with the money growth and its ability to forecast actual future inflation. Bryan and Cecchetti (1993) find that core measures have

“...higher correlations with past money growth and provide improved best forecasts at long horizons (1993). Furthermore, unlike the All Items CPI, the limited-influence estimates appear to be unrelated to future money growth ${ }^{6, "}$

We compare the performance of trimmed means with the weighted mean on varying benchmarks and criteria of evaluation. The idea is to find a measure that best captures the underlying inflation in India void of all transitory fluctuations. In this study, however, we keep ourselves limited to only assessing the distributional characteristics of price changes and deriving the most efficient statistical estimate of central tendency.

\section{Statistical Properties of Cross-section of Price Changes}

\section{$>$ Description of the Data}

The data on WPI in India is compiled and published on a weekly basis by the Office of Economic Advisor (OEA), Ministry of Commerce and Industry. In the year 2000, in keeping with the changes in the structure of the economy, the base year was shifted from 1981-82 to 1993-94. However, a long back series of the WPI at the new base year is still not available from any of the official sources (publications of the Center for Monitoring Indian Economy (CMIE), the Central Statistical Organisation (CSO), OEA and the Reserve Bank of India (RBI)). Farthest back the monthly disaggregate series is available from any official source is starting April 1990 from the Business Beacon Electronic Database of the CMIE. The series with the old base is available till the end of 1996 from the Monthly Abstract of Statistics, published by the CSO. This enables splicing of the

\footnotetext{
${ }^{5}$ Vega and Wynne (2001) for ECB, Bryan, Cecchetti and Wiggins (1997) for US, Roger (1997) for New Zealand, Kearns (1998), Shiratsuka (1997) for Japan, and Mohanty, Rath and Ramaiah (2000) for India are only some examples

${ }^{6}$ Bryan and Cecchetti op cit, p. 23
} 
index to arrive at a series with a common base. As far as level of disaggregation goes, we are constrained by the level till which the data is available at 1993-94 prices, which is 'Level 1' (See Annexure for the list) comprising 38 sub-components.

\section{Splicing}

Splicing Factor $\left(S_{F M}\right)$ can be defined as the ratio $\frac{I_{N E W-M}}{I_{O L D-M}}$ where $I_{N E W-M}$ is the index value at the new base for the common month $M$ for which the data is available at the old base. Clearly, the selection of the month would have a bearing on the 'accuracy' of the splicing factor. To be as 'correct' in our splicing method, we use a different splicing factor for each month, and use the average of the splicing factors for the years 1990, 1991 and 1992 to arrive at the final splicing factor, i.e. our Splicing Factor for month $M$ is derived as

$$
S_{F M}=\frac{1}{3}\left[\frac{I_{N E W-M-1991}}{I_{O L D-M-1991}}+\frac{I_{N E W-M-1992}}{I_{O L D-M-1992}}+\frac{I_{N E W-M-1993}}{I_{O L D-M-1993}}\right]
$$

Further, an issue often ignored is the treatment of the monthly index values for the base year. If we leave the value of the index numbers to 100 for all months for the base year, it creates a distortion in the month-to-month changes in the price index for that year. We use the information available from the 1981-82 base year to get around that problem. We 're-base' the monthly values to ensure consistency with the month-to-month inflation from the old-base data, while leaving the 'year' base value at 100. The sample period is April 1982 - April 2003 (253 observations) and the weights in our study correspond to the base year of 1993-94.

\section{Seasonal Adjustment}

As Cecchetti (1996) notes, while making policy, central banks won't want to respond to seasonal fluctuations in the data. But while seasonality adds to the fluctuations, he notices that only

"... 7\% of the variation in the not-seasonally-adjusted CPI-U, over the full sample, is accounted for by seasonality. ${ }^{7,}$

Kearns (1998) also notes that although a part of the skewness in the cross-sectional data can be explained by the seasonality observed in the prices of the sub-components (particularly those which are often adversely affected by the supply-side shocks and the components for which the prices are set by the government or are otherwise regulated),

\footnotetext{
7 Stephen G. Cecchetti (1996), "Measuring Short-Run Inflation for Central Bankers," NBER Working Paper No. 5786, p. 16
} 
the improvement on seasonally adjusting the data is only marginal. Without any a priori judgment, we start with both unadjusted and seasonally adjusted data.

There are many ways available for seasonally adjusting the data; the easiest and the most convenient is to use appropriate centered moving averages to extract the seasonal factors, forming the basis of the erstwhile X-11 technique of the US Census Bureau, now refined and called the X-11/12 ARIMA procedure.

A technique which has come up in the late ' 90 s and has been popular with some central banks is the TRAMO/SEATS ${ }^{8}$ and this is what we use in our study for seasonal adjustment of the WPI series. TRAMO/SEATS was not an a priori selection, we also tested X-12 ARIMA and found that the automated module of DEMETRA ${ }^{9}$ (software used for implementing seasonal adjustment) failed in finding the parameters of the ARIMA specification in X-12 ARIMA for some sub-components of the WPI (notably for the nonmarket based sub-components that Kearns (1998) notes). With the outlier removal and signal extraction based technique of TRAMO/SEATS however we could find acceptable models for ARIMA errors for all sub-components. To maintain uniformity we stuck to TRAMO/SEATS.

\section{$>$ Preliminary Analysis}

Before we get down to a more detailed analysis of distributional properties of crosssection of price changes, let us look at how the All Commodities WPI has moved over time. Figure 2 shows both the unadjusted and the seasonally adjusted data with trends calculated from the 12, 24, and 36 months CMAs of the data, and the HP Filter trend with the parameter value $(\lambda)$ set at $6400^{10}$. As can be observed, other than the 12 months CMA, the other trends are 'equally smooth'. Without further formal analysis, we discard 12 months CMA at this stage as the benchmark trend to evaluate our estimators. We return to the selection of benchmark problem again later in the next section.

Figure 2

\footnotetext{
8 “Time Series Regressions with ARIMA noise, Missing Observations and Outliers"/"Signal Extraction in ARIMA Time Series"; For technical details on TRAMO/SEATS see Gomez and Maravall (1998)

9 Developed by the Bank of Spain, DEMETRA has been promoted by EUROSTAT, the European Statistical Institute

${ }^{10}$ HP Filter minimizes an asymmetric loss function, with a high $\lambda$ implying higher weight on the smoothness and less weight on goodness of fit; See Hodrick and Prescott (1997) for details
} 

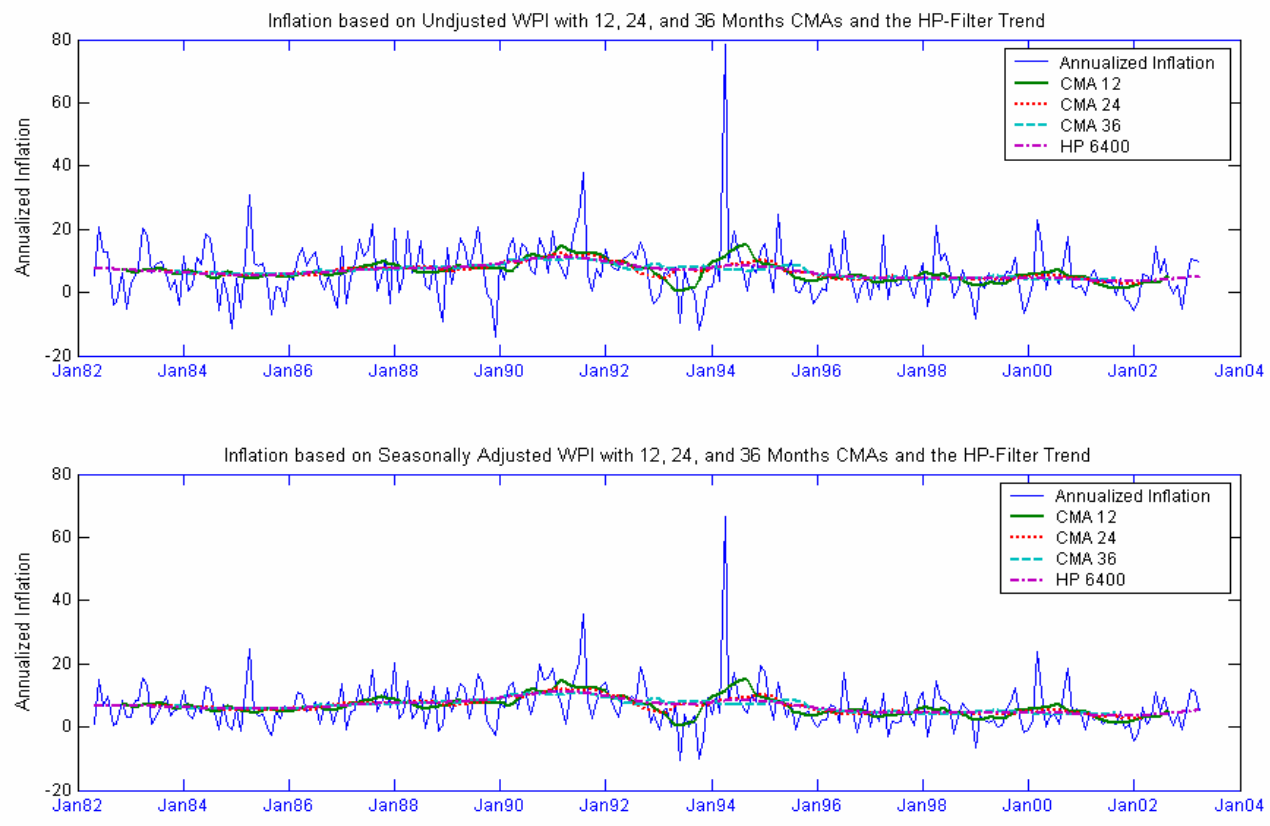

\section{Distributional Characteristics of Price Changes: Individual Sub-components}

In this part we present some descriptive statistics for the 38 sub-components underlying the WPI. To start with, let us look at how the rough probability distributions (PDFs) of these underlying components look like in comparison to the Gaussian. In Figure 3 we plot the rough PDFs (the 'dashed' plots) with the Gaussian having the same mean and standard deviation. Clearly almost all PDFs are 'out of normal'. The plot is indicative of the kind of data we are dealing with. However, we cannot rely on just the shapes of the PDFs to decide on normality of distribution of individual sub-components.

In Table 1 we present first four moments of the distribution of monthly inflation for both the unadjusted and the seasonally adjusted data. The sub-components have been ranked according to the decreasing order of their Co-efficient of Variation $\left(\mathrm{CoV}^{11}\right)$. Note the reduction in CoV (last column in Table 1) in the seasonally adjusted data for almost all the sub-components.

Figure 3

${ }^{11}$ Throughout the study we stick to the following definitions: Coefficient of Variation $(\mathrm{CoV})=\frac{\sigma}{\mu} * 100$;

Skewness Coefficient $(S)=\frac{E\left[\left(x_{i}-\mu\right)^{3}\right]}{\sigma^{3}} ;$ Kurtosis Coefficient $(K)=\frac{E\left[\left(x_{i}-\mu\right)^{4}\right]}{\sigma^{4}}$ 


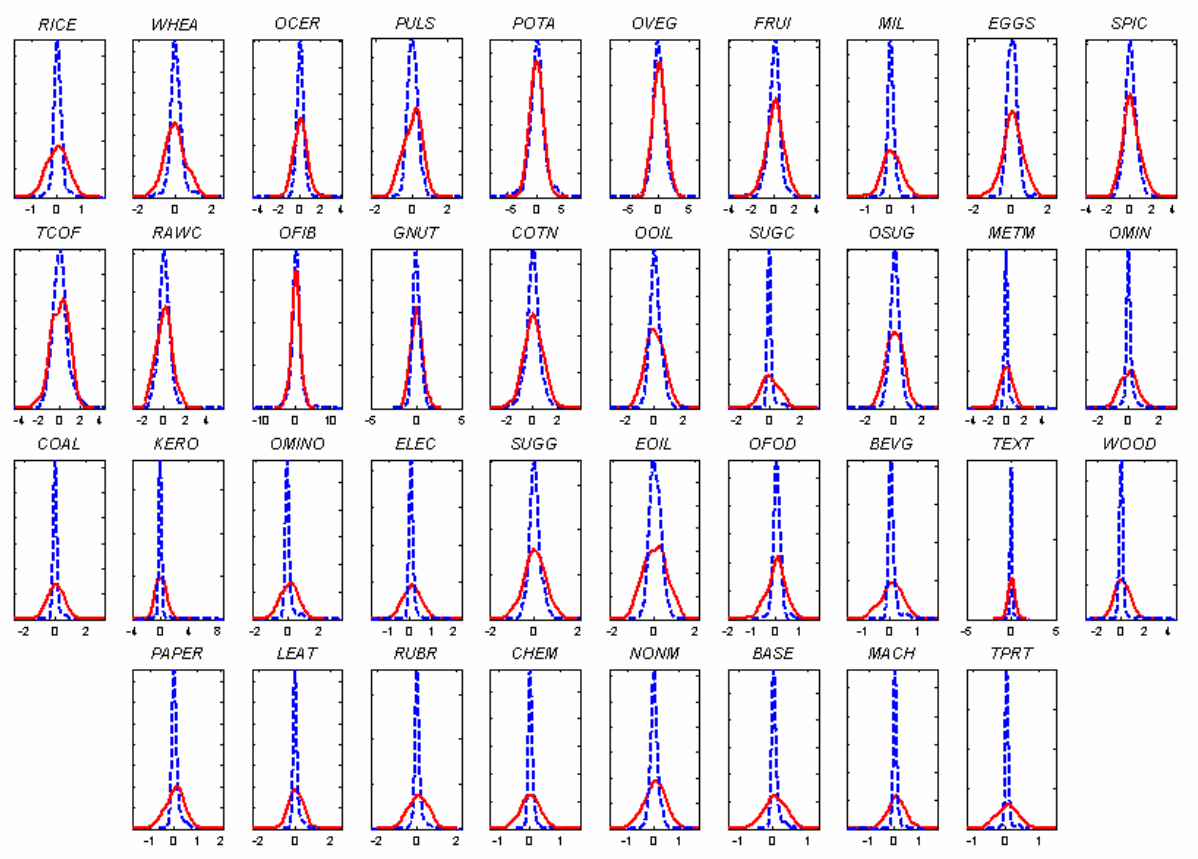

Before we move further, let us take a closer look at the higher order moments of the distribution of price changes. Table 2 presents summary results for skewness and kurtosis of price changes in sub-components. Note that not only are skewness and kurtosis highly non-normal, their standard deviation is also very high suggesting that there is a very high probability of occurrence of such high skewness and kurtosis. See Figure 4 for the plot of skewness and kurtosis for both adjusted and unadjusted data.

As a further check on the non-normality that we notice, we found that all except 2 subcomponents in Table 1 fail the Jarque-Bera test of normality at 1\% level of significance.

We note one more thing from the above tables and plots. While seasonal adjustment reduces the $\mathrm{CoV}$, on an average, it also caused the data to move 'further away from normality', if only slightly. From Figure 2 we saw that seasonally adjustment hardly alters the 'nature' of the fluctuations, albeit the level was reduced To decide on whether to continue our study with unadjusted or seasonally adjusted data we must check how much of 'noise' is removed when the data are seasonally adjusted. 
Table 1

\begin{tabular}{|c|c|c|c|c|c|c|c|c|c|c|c|c|c|}
\hline Category & Mean & Median & StDev & Skew & Kurt & $\mathrm{CoV}$ & Category & Mean & Median & StDev & Skew & Kurt & $\mathrm{CoV}$ \\
\hline \multicolumn{7}{|c|}{ Unadjusted Data } & \multicolumn{7}{|c|}{ Seasonally Adjusted (TRAMO/SEATS) Data } \\
\hline POTA & 0.05 & 0.37 & 2.21 & -0.74 & 4.55 & 4738.40 & POTA & 0.04 & 0.06 & 1.52 & -0.28 & 5.63 & 3889.87 \\
\hline OVEG & 0.07 & 0.22 & 1.54 & -0.45 & 4.44 & 2291.24 & OFIB & 0.08 & 0.11 & 1.50 & -0.05 & 10.07 & 1989.92 \\
\hline OFIB & 0.08 & 0.09 & 1.53 & 0.01 & 9.95 & 1953.17 & OVEG & 0.06 & 0.01 & 1.05 & -0.37 & 6.00 & 1708.86 \\
\hline TCOF & 0.06 & -0.04 & 0.85 & 0.44 & 3.40 & 1409.61 & TCOF & 0.06 & 0.04 & 0.74 & 0.32 & 4.50 & 1262.06 \\
\hline COTN & 0.05 & 0.05 & 0.55 & 0.10 & 5.00 & 1023.66 & COTN & 0.05 & 0.05 & 0.55 & 0.10 & 5.00 & 1023.66 \\
\hline METM & 0.05 & 0.00 & 0.43 & 1.13 & 30.52 & 939.34 & METM & 0.05 & 0.00 & 0.43 & 1.13 & 30.52 & 939.34 \\
\hline RAWC & 0.06 & 0.03 & 0.58 & 1.38 & 10.02 & 915.09 & RAWC & 0.06 & 0.03 & 0.58 & 1.38 & 10.02 & 915.09 \\
\hline FRUI & 0.09 & 0.10 & 0.74 & -0.19 & 6.06 & 798.04 & KERO & 0.08 & 0.00 & 0.57 & 7.69 & 74.21 & 722.09 \\
\hline OOIL & 0.06 & 0.07 & 0.44 & -0.37 & 5.53 & 725.94 & OCER & 0.07 & 0.07 & 0.46 & -0.65 & 16.79 & 674.93 \\
\hline OCER & 0.07 & 0.07 & 0.50 & -0.65 & 13.51 & 723.04 & OMIN & 0.04 & 0.00 & 0.29 & 0.00 & 18.31 & 666.15 \\
\hline KERO & 0.08 & 0.00 & 0.57 & 7.69 & 74.21 & 722.09 & OOIL & 0.06 & 0.03 & 0.40 & -0.22 & 5.95 & 655.09 \\
\hline$G N U T$ & 0.07 & 0.08 & 0.50 & -0.23 & 3.27 & 689.13 & FRUI & 0.09 & 0.14 & 0.58 & -0.32 & 6.38 & 646.74 \\
\hline OSUG & 0.07 & 0.06 & 0.45 & -0.39 & 8.18 & 684.89 & OSUG & 0.06 & 0.07 & 0.40 & -0.38 & 9.01 & 619.76 \\
\hline OMIN & 0.04 & 0.00 & 0.29 & 0.00 & 18.31 & 666.15 & GNUT & 0.07 & 0.05 & 0.42 & -0.07 & 3.68 & 595.39 \\
\hline WHEA & 0.07 & 0.07 & 0.42 & -0.28 & 5.67 & 646.82 & SUGG & 0.05 & 0.03 & 0.26 & 0.77 & 5.99 & 540.52 \\
\hline SUGG & 0.05 & 0.02 & 0.29 & 0.68 & 5.55 & 598.75 & SPIC & 0.10 & 0.09 & 0.54 & -0.12 & 5.09 & 540.25 \\
\hline SPIC & 0.10 & 0.09 & 0.54 & -0.12 & 5.09 & 540.25 & WHEA & 0.07 & 0.03 & 0.34 & 0.77 & 7.18 & 525.75 \\
\hline PULS & 0.08 & 0.05 & 0.38 & 0.76 & 5.37 & 497.46 & WOOD & 0.09 & 0.00 & 0.43 & 3.94 & 26.55 & 495.74 \\
\hline WOOD & 0.09 & 0.00 & 0.43 & 3.94 & 26.55 & 495.74 & EOIL & 0.06 & 0.04 & 0.27 & 0.23 & 3.19 & 443.49 \\
\hline EOIL & 0.06 & 0.04 & 0.27 & 0.23 & 3.19 & 443.49 & PULS & 0.08 & 0.06 & 0.30 & 0.92 & 7.76 & 387.92 \\
\hline EGGS & 0.08 & 0.07 & 0.32 & 0.23 & 4.28 & 429.00 & SUGC & 0.08 & 0.00 & 0.30 & 3.23 & 20.29 & 374.82 \\
\hline LEAT & 0.06 & 0.00 & 0.22 & 0.84 & 20.09 & 386.53 & LEAT & 0.06 & 0.02 & 0.21 & 0.88 & 20.99 & 373.06 \\
\hline SUGC & 0.08 & 0.00 & 0.30 & 3.23 & 20.29 & 374.82 & COAL & 0.09 & 0.00 & 0.32 & 4.69 & 26.65 & 370.95 \\
\hline COAL & 0.09 & 0.00 & 0.32 & 4.69 & 26.65 & 370.95 & OMINO & 0.09 & 0.00 & 0.31 & 3.62 & 21.22 & 359.15 \\
\hline TEXT & 0.05 & 0.04 & 0.17 & 2.33 & 20.59 & 368.92 & EGGS & 0.07 & 0.07 & 0.27 & 0.81 & 5.71 & 358.11 \\
\hline OMINO & 0.09 & 0.00 & 0.31 & 3.62 & 21.22 & 359.15 & TEXT & 0.05 & 0.05 & 0.15 & 3.27 & 34.05 & 322.69 \\
\hline RICE & 0.07 & 0.06 & 0.23 & 0.29 & 7.60 & 354.82 & NONM & 0.06 & 0.04 & 0.16 & 1.25 & 9.90 & 298.76 \\
\hline MIL & 0.07 & 0.05 & 0.24 & 0.96 & 6.14 & 325.94 & RICE & 0.07 & 0.06 & 0.19 & 0.40 & 11.81 & 291.81 \\
\hline NONM & 0.05 & 0.03 & 0.18 & 1.21 & 8.15 & 322.19 & RUBR & 0.04 & 0.02 & 0.11 & 1.33 & 12.28 & 274.41 \\
\hline OFOD & 0.08 & 0.05 & 0.24 & 0.47 & 4.07 & 317.01 & MACH & 0.05 & 0.04 & 0.13 & -2.90 & 50.14 & 242.27 \\
\hline ELEC & 0.09 & 0.00 & 0.27 & 2.80 & 17.44 & 300.88 & OFOD & 0.07 & 0.07 & 0.17 & 0.73 & 6.98 & 229.66 \\
\hline RUBR & 0.04 & 0.01 & 0.12 & 1.26 & 11.57 & 289.31 & MIL & 0.07 & 0.06 & 0.15 & 2.41 & 17.80 & 214.70 \\
\hline MACH & 0.05 & 0.03 & 0.13 & -2.54 & 45.44 & 252.15 & BEVG & 0.09 & 0.04 & 0.18 & 3.07 & 14.93 & 206.74 \\
\hline PAPR & 0.08 & 0.02 & 0.18 & 1.84 & 7.66 & 221.17 & PAPR & 0.08 & 0.04 & 0.16 & 2.34 & 10.29 & 206.57 \\
\hline BEVG & 0.09 & 0.02 & 0.19 & 3.05 & 14.15 & 217.00 & ELEC & 0.09 & 0.06 & 0.18 & 2.70 & 28.55 & 204.13 \\
\hline TPRT & 0.05 & 0.04 & 0.10 & 1.67 & 9.68 & 175.55 & CHEM & 0.06 & 0.04 & 0.11 & 3.36 & 20.33 & 175.37 \\
\hline CHEM & 0.06 & 0.04 & 0.11 & 3.36 & 20.33 & 175.37 & BASE & 0.06 & 0.04 & 0.11 & 2.56 & 11.46 & 170.00 \\
\hline BASE & 0.06 & 0.04 & 0.11 & 2.56 & 11.46 & 170.00 & TPRT & 0.05 & 0.04 & 0.08 & 1.60 & 12.05 & 153.88 \\
\hline
\end{tabular}

Note: The categories highlighted in 'bold' are those for which the Jarque-Bera test failed to reject normality at $1 \%$ level of significance

Table 2

\begin{tabular}{|l|l|l|l|l|l|l|l|l|}
\hline \multirow{2}{*}{ Series/'Moment' } & \multicolumn{4}{|c|}{ Skewness } & \multicolumn{4}{c|}{ Kurtosis } \\
\cline { 2 - 9 } & Min. & Max. & Avg. & StDev. & Min. & Max. & Avg. & StDev. \\
\hline Unadjusted Data & -2.54 & 7.69 & $\mathbf{1 . 1 8}$ & $\mathbf{1 . 8 9}$ & 3.19 & 74.21 & $\mathbf{1 3 . 8 2}$ & $\mathbf{1 3 . 7 0}$ \\
\hline Seas. Adj. Data & -2.9 & 7.69 & $\mathbf{1 . 3 2}$ & $\mathbf{1 . 9}$ & 3.19 & 74.21 & $\mathbf{1 5 . 7 2}$ & $\mathbf{1 4 . 0 9}$ \\
\hline
\end{tabular}

Note: Averages are based on simple mean of skewness and kurtosis in the underlying sub-components 

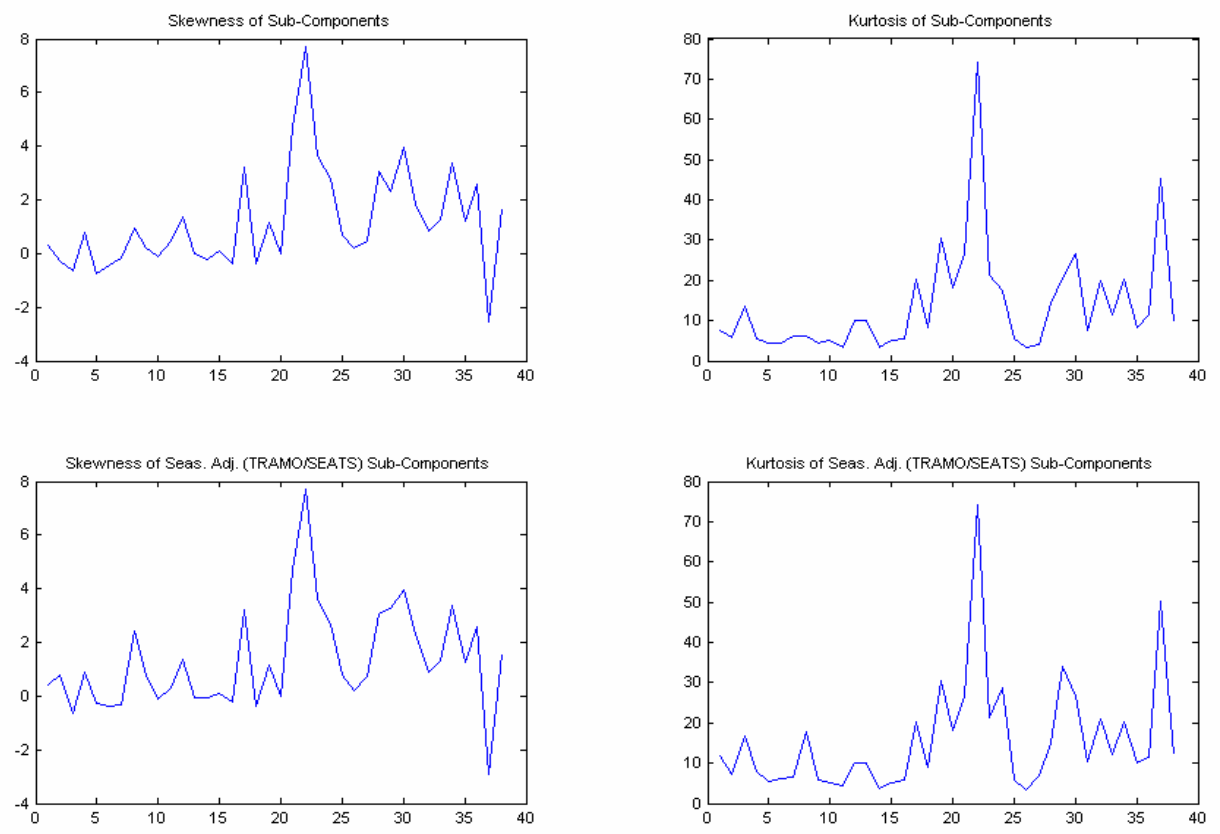

\section{$>$ Measuring 'Noise'}

Cecchetti (1996) measures 'noise' as the proportion of variation in the series attributable to fluctuations of less than a year, defining it as 1 minus the ratio of the variance of 12month inflation to 1-month inflation.

For the components forming the WPI, Table 3 lists 'noise' in both unadjusted and seasonally adjusted data. Note that difference in 'noise' is positive for all the components suggesting that seasonal adjustment does help in removing some noise from the data.

From the table below it is clear that on an average, the 'noise' element is more in the unadjusted series. Since the behaviour of two series is similar in all other respects, for all further analysis we use the seasonally adjusted data. Also, unless otherwise specified, we use the term 'data' to refer to seasonally adjusted data from this point on. 
Table 3

\begin{tabular}{|l|c|c|c|l|c|c|c|}
\hline \multicolumn{9}{|c|}{ 'Noise' } \\
\hline Category & UnAdj. & Seas. Adj. & Diff. & Category & UnAdj. & Seas. Adj. & Diff. \\
\hline RICE & 0.89 & 0.84 & 0.05 & OMIN & 0.92 & 0.92 & 0.00 \\
\hline WHEA & 0.95 & 0.92 & 0.03 & COAL & 0.93 & 0.93 & 0.00 \\
\hline OCER & 0.89 & 0.87 & 0.01 & KERO & 0.85 & 0.85 & 0.00 \\
\hline PULS & 0.93 & 0.89 & 0.04 & OMIN & 0.91 & 0.91 & 0.00 \\
\hline POTA & 0.95 & 0.88 & 0.07 & ELEC & 0.97 & 0.95 & 0.02 \\
\hline OVEG & 0.98 & 0.96 & 0.02 & SUGG & 0.92 & 0.90 & 0.02 \\
\hline FRUI & 0.97 & 0.95 & 0.02 & EOIL & 0.77 & 0.77 & 0.00 \\
\hline MIL & 0.97 & 0.94 & 0.03 & OFOD & 0.95 & 0.90 & 0.05 \\
\hline EGGS & 0.97 & 0.95 & 0.02 & BEVG & 0.91 & 0.90 & 0.01 \\
\hline SPIC & 0.91 & 0.91 & 0.00 & TEXT & 0.84 & 0.79 & 0.05 \\
\hline TCOF & 0.94 & 0.92 & 0.02 & WOOD & 0.83 & 0.83 & 0.00 \\
\hline RAWC & 0.85 & 0.85 & 0.00 & PAPR & 0.85 & 0.83 & 0.02 \\
\hline OFIB & 0.91 & 0.90 & 0.00 & LEAT & 0.88 & 0.87 & 0.01 \\
\hline GNUT & 0.92 & 0.88 & 0.03 & RUBR & 0.87 & 0.86 & 0.01 \\
\hline COTN & 0.93 & 0.93 & 0.00 & CHEM & 0.85 & 0.85 & 0.00 \\
\hline OOIL & 0.87 & 0.84 & 0.03 & NONM & 0.89 & 0.87 & 0.02 \\
\hline SUGC & 0.97 & 0.97 & 0.00 & BASE & 0.80 & 0.80 & 0.00 \\
\hline OSUG & 0.94 & 0.93 & 0.01 & MACH & 0.88 & 0.88 & 0.01 \\
\hline METM & 0.92 & 0.92 & 0.00 & TPRT & 0.86 & 0.83 & 0.03 \\
\hline
\end{tabular}

\section{Transitory Fluctuations in Cross-section of Price Changes}

Now we turn our attention to the properties of the higher order moments of cross-section of price change distribution. Earlier when we looked at the higher order moments of the distribution of individual sub-components we saw that not only did these distributions possess fat tails but they were also on an average positively skewed with high standard deviation. In this section we study the properties of the samples these underlying leptokurtic distributions generate ${ }^{12}$.

Defining aggregate (all commodities) inflation over horizon ' $k$ ' as:

$$
\prod_{t}^{k}=\sum w_{i} \pi_{i t}^{k}
$$

and inflation in individual component ' $i$ ', with weight ' $w_{i}$ ' over horizon ' $k$ ' as:

\footnotetext{
${ }^{12}$ It may not perfectly be accurate to say that underlying distributions 'generate' these samples, because the data from which we have established leptokurtosis is the same. However, doing a Monte Carlo simulation to establish this 'fact' is trivial; an exercise on these lines is conducted by Cecchetti (1996)
} 


$$
\pi_{i t}^{k}=\frac{1}{k} \ln \left(\frac{P_{i t}}{P_{i(t-k)}}\right)
$$

expressions for skewness and kurtosis for horizon ' $k$ ', and time ' $t$ ' take the form:

$$
\begin{aligned}
S_{t}^{k}= & \frac{\sum_{i} w_{i}\left(\pi_{i t}^{k}-\prod_{t}^{k}\right)^{3}}{\sigma^{3}} \\
K_{t}^{k} & =\frac{\sum_{i} w_{i}\left(\pi_{i t}^{k}-\prod_{t}^{k}\right)^{4}}{\sigma^{4}}
\end{aligned}
$$

Lest there be any confusion, note that in above expressions, $\sigma=\left[\sum_{i} w_{i}\left(\pi_{i t}^{k}-\prod_{t}^{k}\right)^{2}\right]^{1 / 2}$

In Figure 5 we plot weighted skewness and kurtosis for monthly inflation for the entire sample period (difference from Figure $\mathbf{1}$ is that this one is based on seasonally adjusted data; as we noted earlier too, there is not much difference between the two). As noticed in Figure 1, although skewness on an average is around zero, it exhibit lots of fluctuations. Even kurtosis not only exceeds 50 quite often, it is also characterized by a high standard deviation.

The skewness and kurtosis that we observe in the monthly series is because with such high frequency data there will be some components every month for which the prices will change by amount 'more than normal', but over time these extremities settle down, bringing the distribution close to Gaussian. Figure 6 plots average and standard deviation (in the lower panel) of weighted skewness and kurtosis of changes in WPI prices for horizons ranging from 1 month to 72 months. We see that with increasing horizon both mean and standard deviation of weighted skewness and kurtosis decline (we are not able to account for the jump around 30 months for kurtosis and around 40 months for mean of skewness).

Note that even though both skewness and kurtosis decline with horizon, saturation occurs only after around 30-40 months, i.e. after as long as 3 years. Also, although the absolute value of average weighted skewness is not very high, the standard deviation of skewness (of order more than 3-5 times the mean) is troubling. As a further check on the normality of the cross-section distributions, we found the Jarque-Bera test rejected normality for all 72 horizons at $1 \%$ level of significance. With such a high positive skewness in the distribution of cross-section of price changes, weighted mean cannot be an efficient estimator of inflation, for whatever reasonable horizon we would want to calculate it for. 
Figure 5
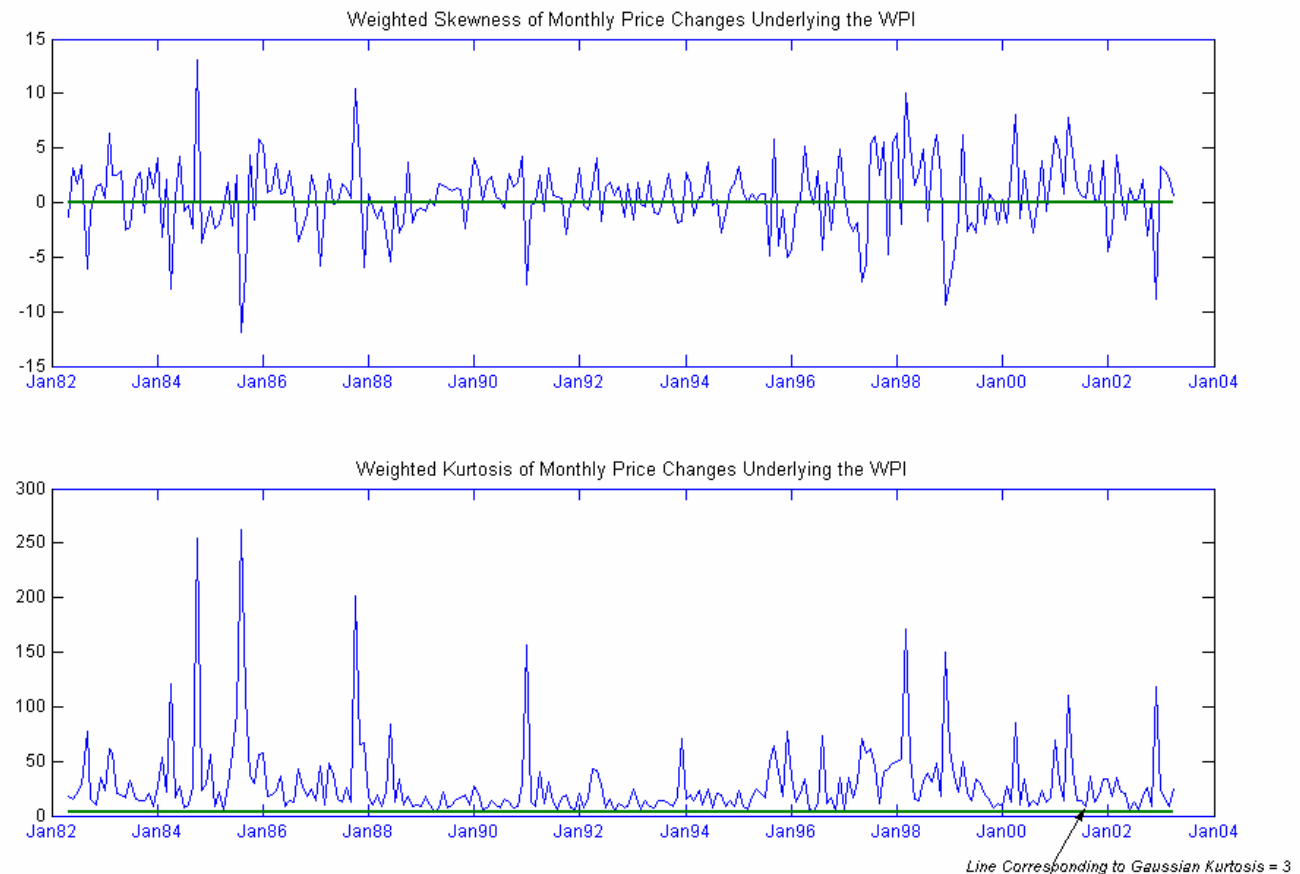

Figure 6
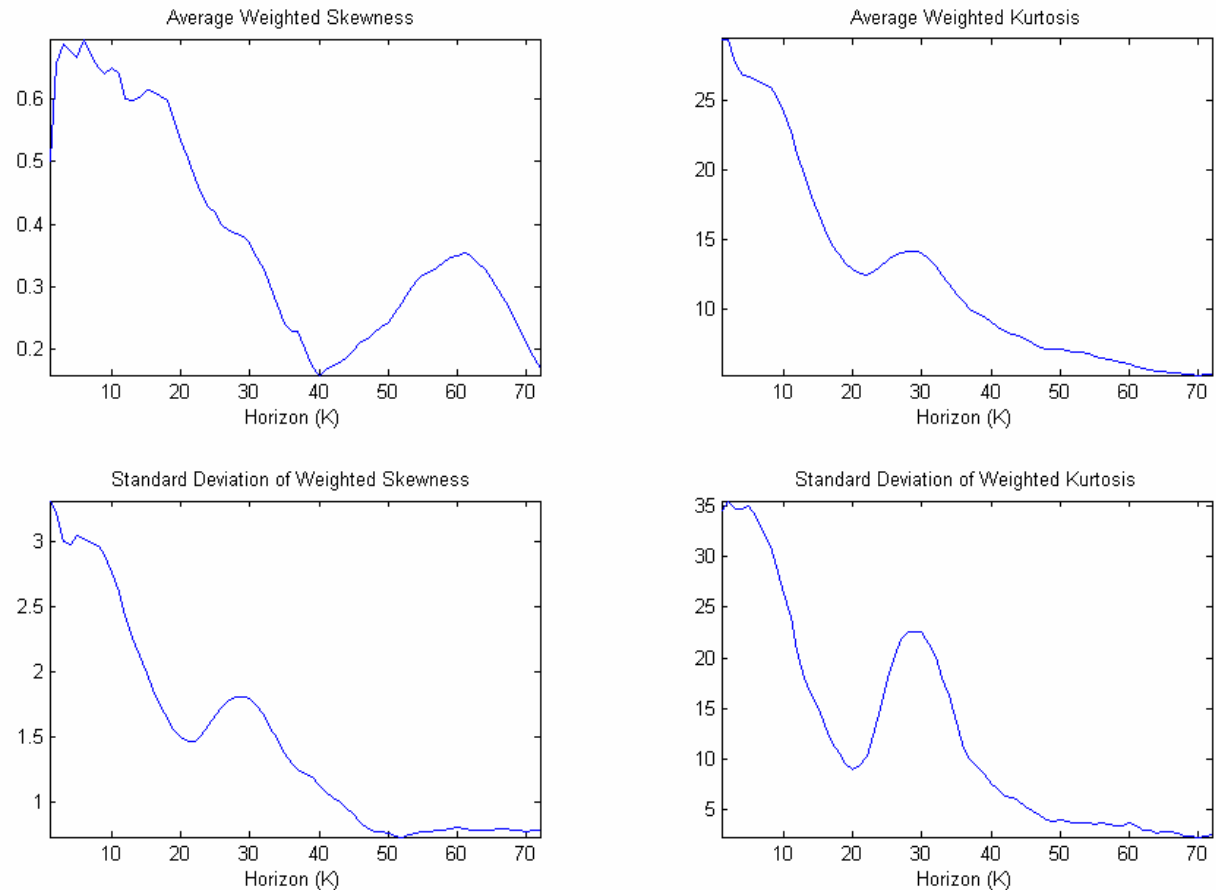


\section{Trimmed Means as Efficient Estimators of Inflation}

Now that we have seen that weighted mean cannot be an efficient estimator of inflation, we need to look for another class of estimators. High skewness itself suggests a solution. Since efficiency of mean as the measure of central tendency is marred by the transitory fluctuations leading to positive skewness, we can get a better estimate if we just ignore the elements causing skewness in price change distribution. Trimmed mean, belonging to the class of limited influence estimators do just that. Only looking at the 'core' of the probability distribution, tails are ignored and the mean is calculated using the remaining portion of the distribution. A special case of trimmed mean estimators is the familiar median, in which we just focus on the central value, ignoring $50 \%$ 'tail' on each side.

Inflation for horizon $k$, calculated by trimming $\alpha_{1}$ and $\alpha_{2}$ percents from the left and tail respectively can then be defined as:

$$
\prod_{\alpha_{1}, \alpha_{2}}^{k}=\frac{\sum_{i \in I_{\alpha_{1}, \alpha_{2}}} w_{i k} \pi_{i k}}{\sum_{i \in I_{\alpha_{1}, \alpha_{2}}} w_{i}}
$$

In the above expression $I_{\alpha_{1}, \alpha_{2}}$ is the 'indicator set' which contains the data which are to be included in the central 'core' of the distribution. One way of implementing this is to rank the data in increasing order along with the corresponding weights, trim the lower and upper tails of the discrete distribution, given the values of $\alpha_{1}$ and $\alpha_{2}$, and scale the weighted mean appropriately as in equation [6].

\section{Selecting the Optimal Trimming Pattern: Evaluation}

Before we present our results for trimmed means, we need to spend sometime on selection of benchmark for evaluating these trimmed means. If we just stick to the integer value of trims there are 2,500 (1\% - 50\% from each tail) candidates for trimmed mean. Thus we need some criteria that would help us locate the optimal trimming pattern given the data. The criteria of evaluation should not only be the smoothness in the trend series, but also its ability to absorb all inertia resulting from transitory fluctuations.

Bryan, Cecchetti and Wiggins (1997) suggested 36 month CMA based on an earlier study by Cecchetti (1996) on the Consumer Price Index for the US. Most studies on measuring core inflation have since used this benchmark for evaluation of trimmed means. The study done in the Indian context by Mohanty, Rath and Ramaiah (2000) also uses the same 36 month CMA. We let our data do the talking. 
From Figure 6 we saw that after around 3 years, both skewness and kurtosis tended to stabilize, including their standard deviations. This is an indication that 30 or more month's centered moving average would be apt as a benchmark for the Indian data. In Figure 2 we saw that the 12 month CMA showed considerable fluctuations when compared to 24 and 36 months CMA and the trend derived from HP filter. With the information on decreasing skewness and kurtosis after around 36 months, we can safely discard 24 months CMA also as the benchmark. Other than CMAs, an HP Filter trend estimate with a high value of $\lambda^{13}$ could potentially be the 'most smooth' estimate of trend. One could argue why not just use the HP filter in real time to compute the trend inflation. The problem is that just like most two-way of filters estimates from HP filter also suffer from the end-of-sample problems related to loss of information at end-points (See Baxter and King (1999) for critique and details; Ahumada and Garegnani (1999) provides a summary of debate surrounding the use of HP-Filter in practice).

To evaluate our trimmed means we use 36, 42, 48 CMAs (we don't go beyond 48 months keeping in mind the jump in skewness again around 50 months) and the HP filter with the parameter value set at 4800, 9600 and 14,400. The selection of the value of $\lambda$ is done by taking multiples of 3 of the 'default' value for quarterly data ${ }^{14}$, which is 1600 .

\section{Criteria of Evaluation}

After having decided on the benchmark, the last thing we need to decide to consider is the criteria of evaluation. Two standard criteria are the Mean Absolute Deviation (MAD) and the Root Mean Square Error (RMSE). Whereas MAD weights all deviations equally, RMSE penalizes the extreme deviations more by 'squaring' them. Other than these two we also look at an Asymmetric Loss Function, which penalizes more when deviation from the benchmark are on the positive side and when inflation is near zero (using our judgment here, we assume $2 \%$ inflation as the level below which central bank would become wary of deflation). The form of the ALF we use is

$$
A L F=\sqrt{\frac{\sum\left[\lambda_{1}\left(\pi_{i}-\Pi\right)^{2}+\lambda_{2}\left(\pi_{i}-\Pi\right)^{2}+\lambda_{3}\left(\pi_{i}-\Pi\right)^{2}\right]}{N}}
$$

$\lambda_{1}=3$ if $\pi \leq 2$, otherwise 0 ;

$\lambda_{2}=1$ if $2<\pi<\prod$, otherwise 0

$\lambda_{3}=2$ if $\pi \geq \prod$, otherwise 0

\footnotetext{
${ }^{13}$ See Hodrick and Prescott (1997) for details

14 ibid and Ahumada and Garegnani (1999)
} 
The exact values of the parameter used are arguable, but we believe that in spirit the above formulation catches the asymmetry in the loss function. Now we present our results, mostly graphically.

\section{Results and Discussion}

Figures 7, 8 and 9 present the performance of trimmed means against different trend proxies (essentially similar, we show results for CMA 36, CMA 48, HP 4800 and HP 14400) on MAD, RMSE and ALF respectively. It is clear that for all cases considered, the higher the trimming from the tails, the better the performance on the chosen criteria. As is apparent from the plots, for all benchmarks and evaluation criteria, the minima occur around the median value. The trims from the left and right tail corresponding to minima are $49 \%$ and $50 \%$. Also, note that all these plots 'look' quite similar, indicating that our result is robust to the benchmark and criteria of evaluation.

Even though we notice reduction in deviations from benchmark it does not necessarily imply that minima represent an 'optimal' trimming pattern. For this we need to see how much improvement occurs relative to the weighted mean and median. In Tables 4 and 5 we present MAD, RMSE and ALF values for mean and weighted median. We compare this with the performance of trimmed means (on trend based on CMA 48), presented in Figure 10. Clearly, as the graphs above and the tables below show, there is a huge gain by trimming the distribution whatever our criteria of evaluation. ${ }^{15}$

However, unlike what Bryan and Cecchetti (1993) and Bryan, Cecchetti and Wiggins (1997) found, the gains are not very large for small trims, and the rate of fall in $\mathrm{MAD} / \mathrm{RMSE} / \mathrm{ALF}$ against total trim is quite high. As a last check we compare the temporal evolution all key measures over our entire sample period in Figure 11. It is clear that 49/50 Trimmed Mean outperforms all other measures when compared to CMA 48 .

\footnotetext{
${ }^{15}$ Increase in the value of MAD etc. as the order in CMA or 'penalty' in HP filter is increased can be explained by the fact, that 'smoother' the underlying trend, more would be the deviations on average from 'the mean'
} 
Figure 7
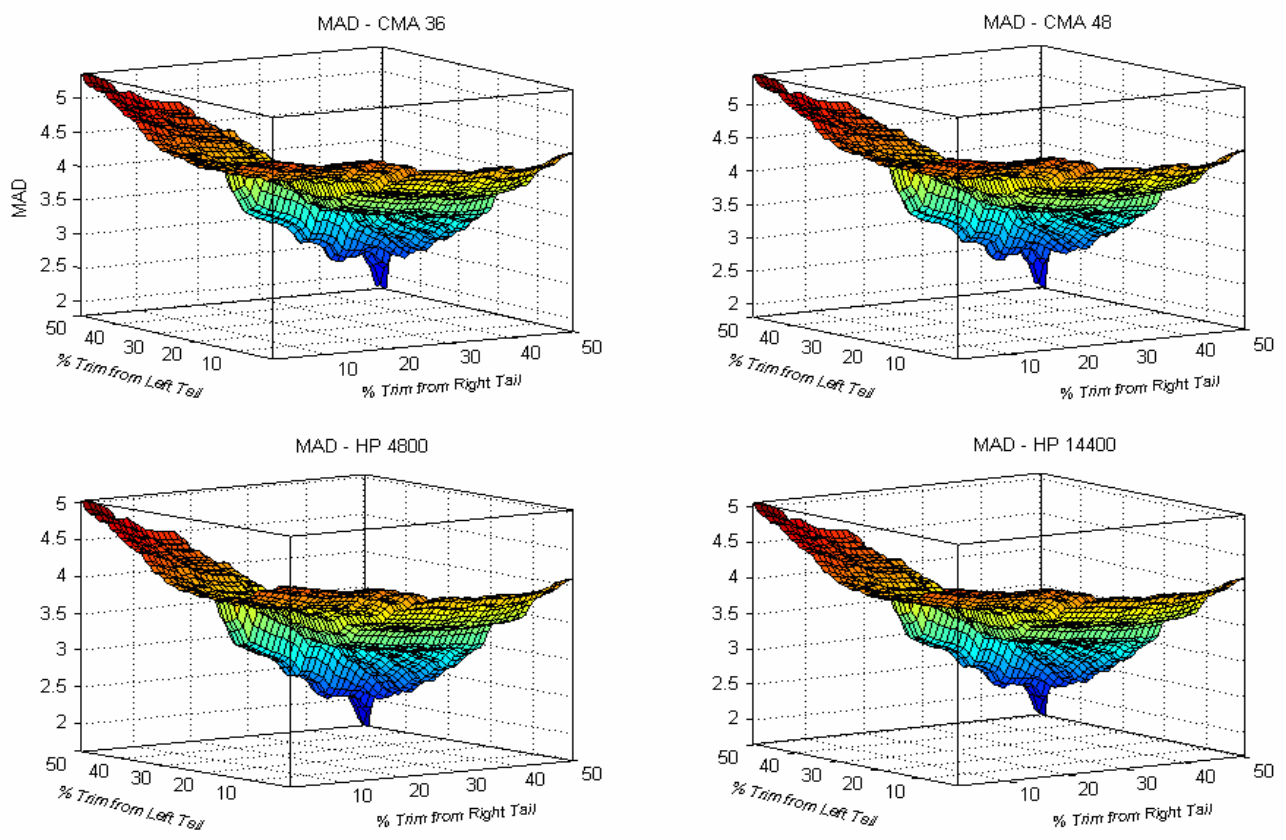

Figure 8
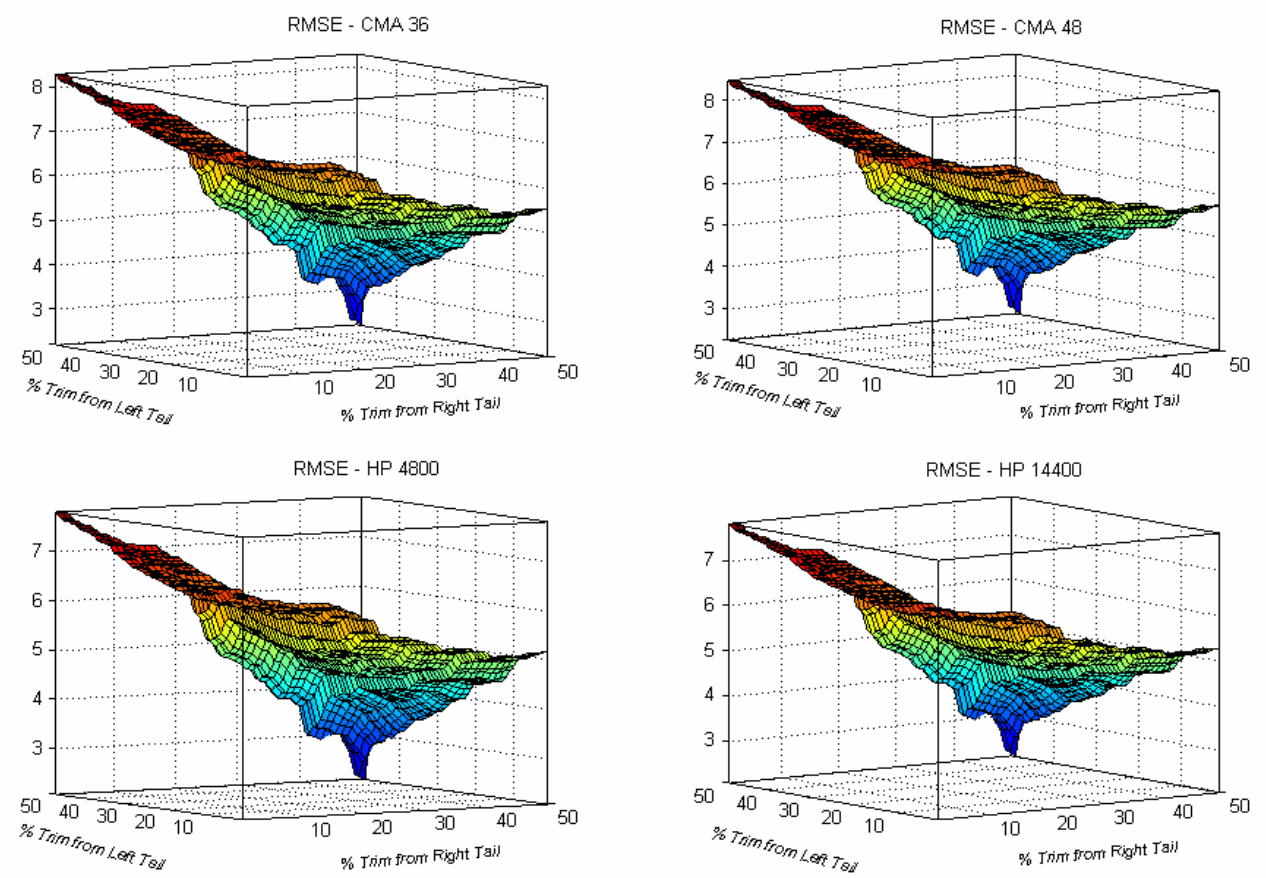
Figure 9
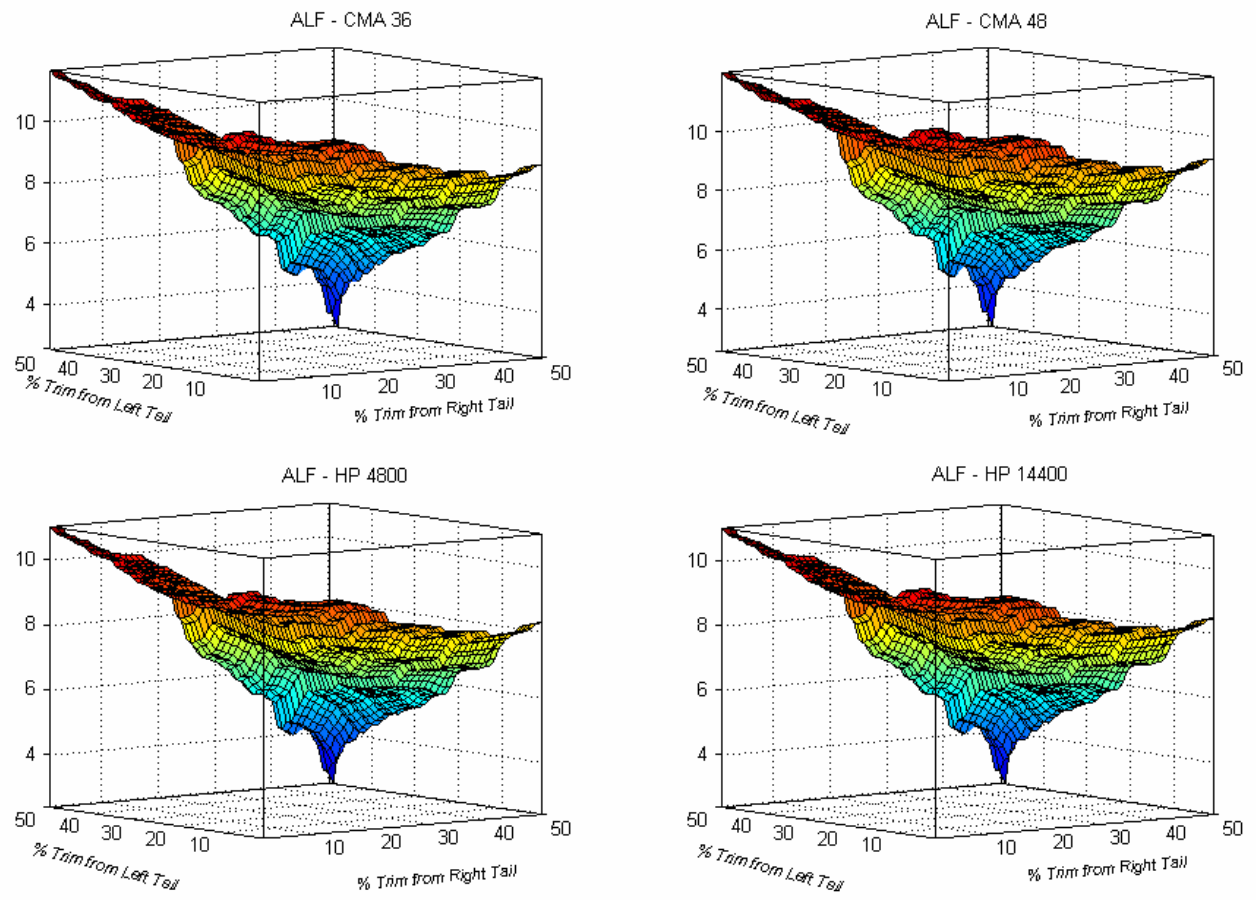

Figure 10
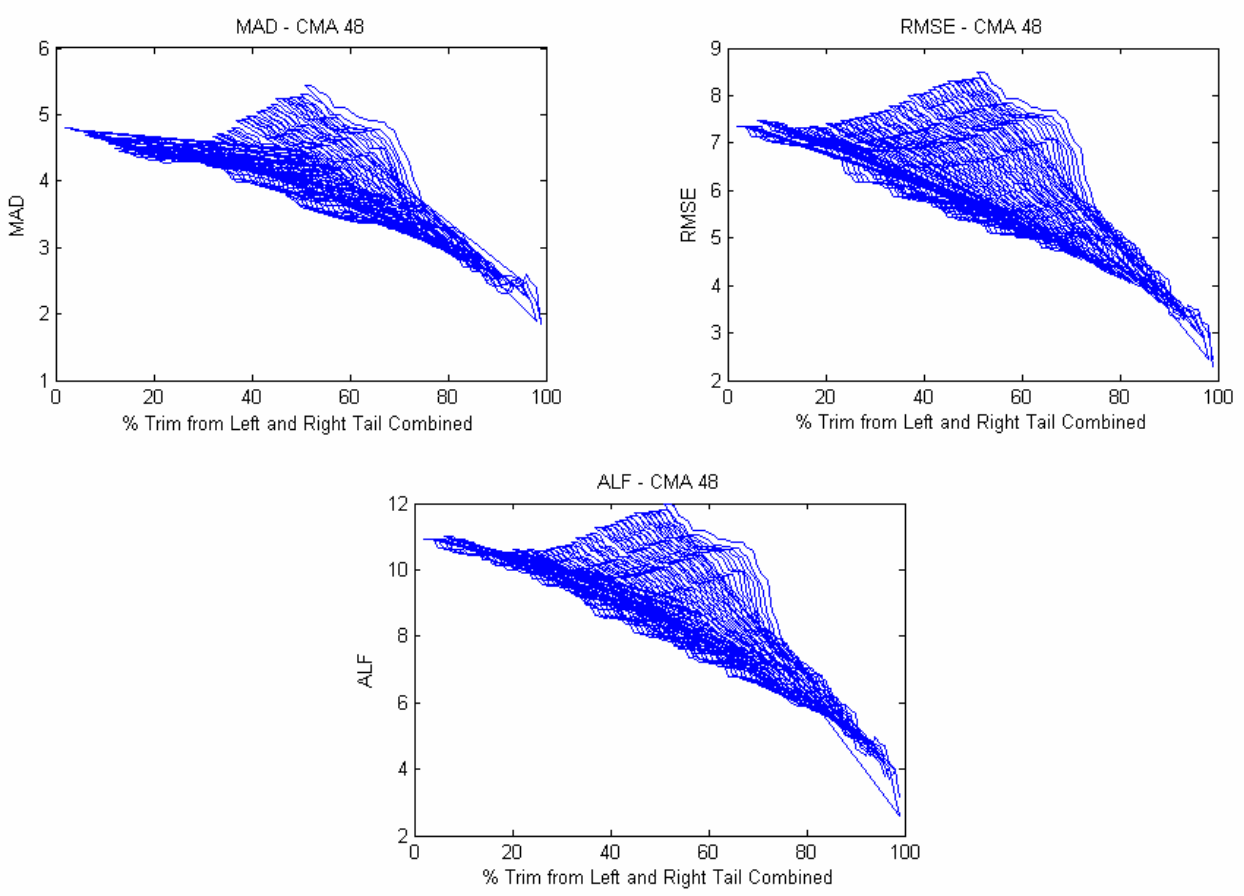
Table 4

\begin{tabular}{|c|l|l|l|l|l|l|}
\hline \multicolumn{7}{|c|}{ Weighted Mean } \\
\hline Benchmark/Criteria & CMA36 & CMA42 & CMA48 & HP4800 & HP9600 & HP14400 \\
\hline MAD & 4.6233 & 4.7047 & 4.7915 & 4.3369 & 4.3757 & 4.3990 \\
\hline RMSE & 7.1289 & 7.2537 & 7.3847 & 6.6237 & 6.6928 & 3.7247 \\
\hline ALF & 10.5612 & 10.7705 & 10.9727 & 9.8223 & 9.9409 & 9.9947 \\
\hline
\end{tabular}

Table 5

\begin{tabular}{|c|l|l|l|l|l|l|}
\hline \multicolumn{7}{|c|}{ Weighted Median } \\
\hline Benchmark/Criteria & CMA36 & CMA42 & CMA48 & HP4800 & HP9600 & HP14400 \\
\hline MAD & 3.6941 & 3.8010 & 3.8507 & 3.4304 & 3.4857 & 3.5136 \\
\hline RMSE & 5.7392 & 5.8688 & 5.9669 & 5.2775 & 5.3411 & 5.3712 \\
\hline ALF & 8.4434 & 8.6407 & 8.7541 & 7.7217 & 7.8349 & 7.8870 \\
\hline
\end{tabular}

Table 6

\begin{tabular}{|c|l|l|l|l|l|l|}
\hline \multicolumn{7}{|c|}{ 49/50 Trimmed Mean } \\
\hline Benchmark/Criteria & CMA36 & CMA42 & CMA48 & HP4800 & HP9600 & HP14400 \\
\hline MAD & 1.7572 & 1.8006 & 1.8188 & 1.6303 & 1.6454 & 1.6540 \\
\hline RMSE & 2.2176 & 2.2395 & 2.2604 & 2.1014 & 2.0891 & 2.0905 \\
\hline ALF & 2.5252 & 2.5887 & 2.6058 & 2.3874 & 2.3939 & 2.4047 \\
\hline
\end{tabular}

Figure 11

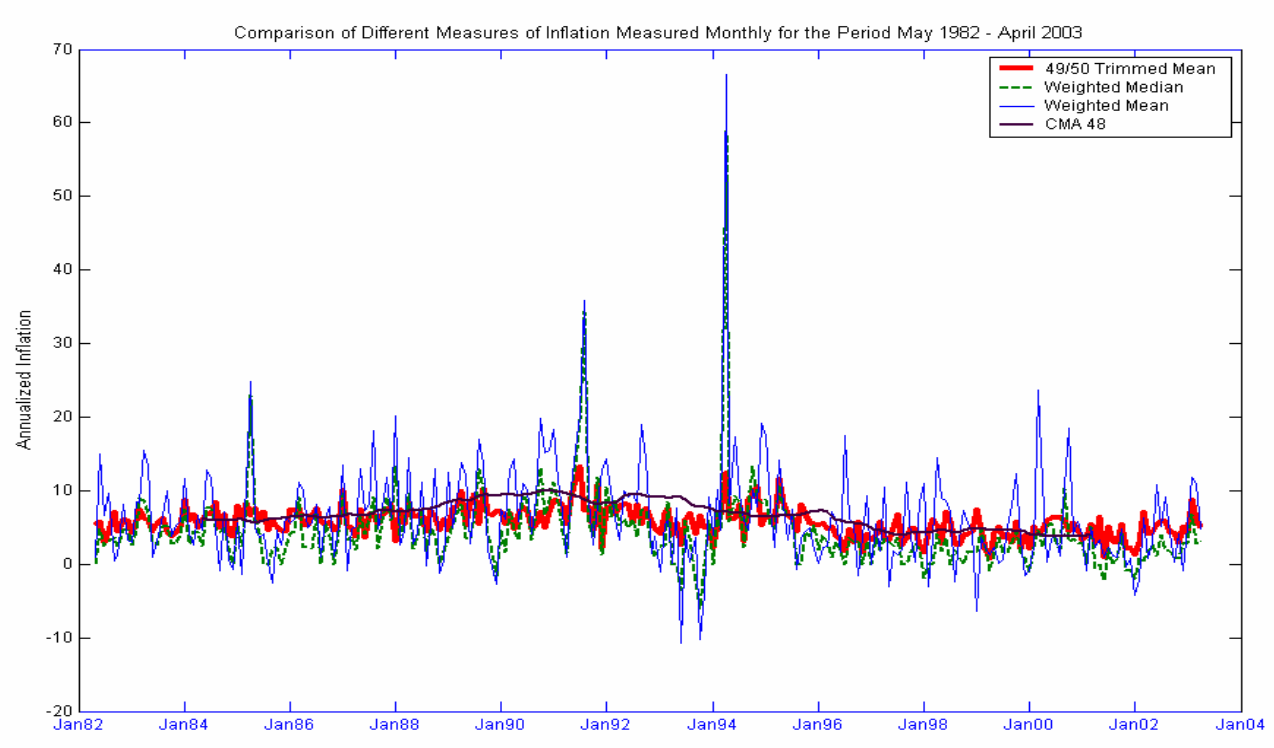




\section{References}

Ahumada, H. and Garegnani, M.L (1999), "Hodrick Prescott Filters in Practice," Central Bank of Turkey Working Paper, April

Balke, Nathan S., and Mark A. Wynne, "Supply Shocks and the Distribution of Price Changes," FRB Dallas Economic Review, 1996, pp. 10-18.

Ball, Laurence, and Mankiw, N. Gregory (1995), "Relative-Price Changes as Aggregate Supply Shocks," Quarterly Journal of Economic Studies, 110(1), 161- 93

Baxter, M \& King, R. J. (1999). Measuring business cycles: Approximate band-pass filters for economic time series, Review of Economics and Statistics, 81(4), 575593.

Blinder, A. (1982), "The Anatomy of Double Digit Inflation in the 1970s," in R.E. Hall (ed.), Inflation: Causes and Effects, The University of Chicago Press for NBER, 261-282

Bryan, Michael F., \& Cecchetti, Stephen G. (1993) “Measuring Core Inflation,” NBER Working Paper No. 4303

Bryan, Michael F., and Cecchetti, Stephen G. (1996), "Inflation and the Distribution of Price Changes," NBER Working Paper No. 5793

Bryan, Michael F., Cecchetti, Stephen G, and Wiggins, Rodney L II (1997), "Efficient Inflation Estimation," NBER Working Paper No. 6183

Cecchetti, Stephen G. (1996), "Measuring Short-Run Inflation for Central Bankers," NBER Working Paper No. 5786

Hodrick, R. J. and Prescott, E.C. (1997), "Post-war Business Cycles: An Empirical Investigation," Journal of Money, Credit and Banking 29(1), 1-16

Gomez and Maravall (1998), "Seasonal Adjustment and Signal Extraction in Economic Time Series, Banco de Espana, Working Paper 9809

Kearns, Jonathan (1998). The distribution and measurement of inflation, Reserve Bank of Australia Research Discussion Paper 9810

Mohanty, D., Rath, P.R. and Ramaiah, M. (2000), "Measures of Core Inflation for India," Economic and Political Weekly, January 29, 273-282

Roger, S. (1997), “A Robust Measure of Core Inflation in New Zealand," Reserve Bank of New Zealand Paper G7/7

Shiratsuka, S (1997), "Inflation Measures for Monetary Policy: Measuring the Underlying Inflation Trend and Implication for Monetary Policy Implementation," Institute for Monetary and Economic Studies, Bank of Japan, December

Vega, Juan-Luis and Wynne, Mark A (2001), „A First Assessment of Some Measures of Core Inflation for the Euro Area, $E C B$ Working Paper No. 53 


\section{Annexure}

\begin{tabular}{|c|c|c|}
\hline Sr. No. & Category & Abbreviation \\
\hline 1 & Potatoes & POTA \\
\hline 2 & Other Vegetables & OVEG \\
\hline 3 & Other Fibres & OFIB \\
\hline 4 & Tea and Coffee & TCOF \\
\hline 5 & Cotton & COTN \\
\hline 6 & Metallic Minerals & METM \\
\hline 7 & Raw Cotton & RAWC \\
\hline 8 & Fruits & FRUI \\
\hline 9 & Other Oil Minerals & OOIL \\
\hline 10 & Other Cereals & OCER \\
\hline 11 & Kerosene & KERO \\
\hline 12 & Groundnut & GNUT \\
\hline 13 & Other Sugar Items & OSUG \\
\hline 14 & Other Minerals & OMIN \\
\hline 15 & Wheat & WHEA \\
\hline 16 & Sugar Group & SUGG \\
\hline 17 & Spices & SPIC \\
\hline 18 & Pulses & PULS \\
\hline 19 & Wood & WOOD \\
\hline 20 & Edible Oils & EOIL \\
\hline 21 & Eggs & EGGS \\
\hline 22 & Leather & LEAT \\
\hline 23 & Sugarcane & SUGC \\
\hline 24 & Coal & COAL \\
\hline 25 & Textile & TEXT \\
\hline 26 & Other Mineral Oils & OMINO \\
\hline 27 & Rice & RICE \\
\hline 28 & Milk & MIL \\
\hline 29 & Non Metallic Minerals & NONM \\
\hline 30 & Other Food Group Items & OFOD \\
\hline 31 & Electrical Machinery & ELEC \\
\hline 32 & Rubber & RUBR \\
\hline 33 & Machines & $\mathrm{MACH}$ \\
\hline 34 & Paper and Pulp & PAPR \\
\hline 35 & Beverages & BEVG \\
\hline 36 & Transport & TPRT \\
\hline 37 & Chemicals & CHEM \\
\hline 38 & Basic Metals & BASE \\
\hline
\end{tabular}

